\title{
COLEÇÃO DIDÁTICO-CIENTÍFICA DE LIXO NO AMBIENTE MARINHO EM GOVERNADOR CELSO RAMOS (SC): DA MONTAGEM À AUTOAVALIAÇÃO
}

\author{
Bruna Costa ${ }^{1}$ \\ Walter Martin Widmer²
}

Resumo: $O$ lixo no mar é um problema crescente e mundial, impulsionando debates na busca de soluções. A coleção didático-científica de lixo no mar é uma ferramenta de Educação Ambiental marinho-costeira facilitadora na tratativa e abordagem do tema. Este trabalho relata a experiência de montagem de uma coleção, que ocorreu através da coleta do macrolixo encontrado em praias de Governador Celso Ramos, entre 2019 e 2020. Parcerias viabilizaram a localização física e a operação da coleção, que incluiu uma versão resumida em ambiente on-line, respeitando o distanciamento social exigido pela pandemia Covid-19. Os resultados da autoavaliação foram positivos, viabilizando, assim, uma importante ferramenta dinâmica de divulgação científica e de sensibilização ambiental.

Palavras-chave: Educação Ambiental; Coleção Científica; Covid-19; Macrolixo; Praia.

Abstract: Marine litter is considered a growing and worldwide problem, which has sparked debates for solutions. The didactic-scientific collection of marine debris is a marine and coastal environmental education tool that facilitates the treatment and approach of the theme. This study describes the structuration of this collection, which was assembled with macro items found on Governador Celso Ramos beaches (a municipality in south Brazil), between 2019 and 2020. Partnerships enabled the location and operation of the collection, which includes an abridged online version, respecting the required social distance by the Covid-19 pandemic. The results of a self-evaluation were positive, enabling an important dynamic tool for scientific dissemination and environmental awareness in the municipality.

Keywords: Environmental Education; Scientific Collection; Covid-19; Macro Debris; Beach.

1 Instituto Federal de Santa Catarina, campus Florianópolis, SC, E-mail: brunacosta-c@hotmail.com 2 Instituto Federal de Santa Catarina, campus Florianópolis, SC, E-mail: walter.widmer@ifsc.edu.br 


\section{Introdução}

A zona costeira é uma área estratégica para o país por conta da sua riqueza de ecossistemas, os quais incluem restingas, manguezais e recifes de corais, assim como por sua beleza singular e recursos naturais, além da diversidade de atividades econômicas relevantes que são desenvolvidas nessa região, como a atividade portuária, o turismo de "sol e praia" e a pesca (ANDRADE; SCHERER, 2014). Diversas atividades humanas ameaçam a funcionalidade da zona costeira. Estudos apontam, por exemplo, que a presença de lixo nas praias afeta negativamente a avaliação cênica das mesmas e, consequentemente, o turismo (WILLIAMS, et al., 2016; CORRAINI et al., 2018). O Ministério do Meio Ambiente também relata que o lixo ameaça os trabalhos de conservação ambiental realizado nas Unidades de Conservação (UC) em todo o território nacional para proteger o patrimônio natural brasileiro (BRASIL, 2014).

Conceitualmente, lixo no mar é todo resíduo sólido que de alguma forma foi parar no ambiente marinho. Considerando ainda que $80 \%$ do lixo marinho tem sua origem no continente, o enfrentamento dessa problemática requer uma abordagem em várias frentes, como, por exemplo, a gestão eficiente dos resíduos sólidos nos municípios, mudanças de hábitos de consumo e de descarte do lixo, identificação e responsabilização de poluidores ambientais e uma sólida e consistente Educação Ambiental da sociedade civil (BRASIL, 2019).

Nos últimos anos, o lixo no mar se tornou um dos tipos de poluição mais difundidos. No contexto mundial, a Assembleia Geral das Nações Unidas aprovou, em 2015, a Agenda 2030 para o desenvolvimento sustentável. Nela, foram estabelecidos os Objetivos de Desenvolvimento Sustentável (ODS), que devem ser alcançados por todos os países até o ano 2030. O Objetivo 4, Educação de Qualidade, tem como meta até 2030 garantir que todos os alunos adquiram conhecimentos e habilidades necessárias para promover 0 desenvolvimento sustentável. O Objetivo 14 da Agenda 2030, Vida na Água, visa conservar e promover o uso sustentável dos oceanos, dos mares e dos recursos marinhos (ONU, 2020). Nesse contexto, o Governo Federal Brasileiro, por meio do Ministério do Meio Ambiente, lançou em 2019 o Plano de Combate ao Lixo no Mar, por meio do qual o governo convoca toda a sociedade na busca e tratativas do problema do lixo no mar, que é considerado crescente e mundial (MMA, 2019).

O Brasil no ano de 2000 através da Lei no 9.985 instituiu o Sistema Nacional de Unidades de Conservação da Natureza, ou seja, espaços territoriais e seus recursos ambientais, incluindo as águas jurisdicionais, com características naturais relevantes, legalmente instituídos pelo Poder Público, espaços que são protegidos por força de Lei com o objetivo de sua conservação. O Estado de Santa Catarina ainda dispõe de instrumentos de gestão costeira e apresenta uma produção científica razoável, porém, há uma lacuna de conhecimento em diversas áreas, em especial aquelas relacionadas 
ao conhecimento do mar e seus recursos. Santa Catarina está bastante aquém do desejável quanto à educação para a sustentabilidade. Existem iniciativas isoladas de produção de material educativo com relação à zona costeira e a apresentação deste material de maneira formal e informal é ainda insatisfatória (ANDRADE; SCHERER, 2014).

A Política Nacional de Educação Ambiental foi instituída em1999 pela lei no 9.795. Entende-se por Educação Ambiental (EA) os processos por meio dos quais são construídos conhecimentos e atitudes voltadas para a conservação do meio ambiente, sendo um componente essencial e permanente no qual todos devem ter o direito à Educação Ambiental (BRASIL, 1999).

Segundo Torres et al. (2019), os programas educacionais são eficazes no aumento do conhecimento do conteúdo científico e existem maneiras eficientes de melhorar os programas existentes de educação informal voltados para a prevenção de lixo no mar.

Para Souza Filho et al. (2018), há pouco conhecimento da população no que se refere à Educação Ambiental Marinha e Costeira (EAMC). Entre os diversos instrumentos de EAMC, destacam-se aqui as coleções didáticocientíficas. Tais coleções podem reunir exemplares de animais, fósseis e outros tipos de amostras de interesse oceanográfico. Todas essas coleções são comuns em instituições de ensino e pesquisa. No entanto, com o desenvolvimento de novas linhas de pesquisa, há a necessidade da formação de novas coleções, reunindo exemplares relacionados aos novos objetos de estudo e esclarecendo diferentes processos a eles relacionados (ALVES et al., 2010).

As confecções de coleções reunindo e organizando objetos de valor científico são uma ferramenta fácil e prática no apoio à sensibilização e à Educação Ambiental. As coleções possuem uma vertente conservacionista da Educação Ambiental, sendo promotoras de reflexões intelectuais e envolvem os participantes nas temáticas de estudo (SILVA; KRELLING, 2019).

No campo da educação formal, as atividades educacionais de caráter prático e lúdico demonstraram ser bastante atrativas aos estudantes, criando expectativa e interesse pelo tema abordado. Dessa forma, trabalhar temas como lixo no mar pode ser uma excelente oportunidade de estímulo à sensibilização de estudantes (SANTANA NETO et al., 2011).

Apesar da importância das coleções, foram mapeadas apenas sete coleções didático-científicas referentes ao tema "lixo marinho" existentes no Brasil. As datas de criação das referidas coleções variam entre os anos de 1999 e 2017. Portanto, foram necessárias quase duas décadas para a criação dessas sete coleções de lixo em ambientes marinhos (SOUZA FILHO et al., 2018).

Recentemente, várias outras iniciativas juntamente com essas coleções mais antigas formaram uma Rede Nacional de Coleções de Lixo Marinho (RECOLIXO). Essa rede tem representantes em vários pontos do Brasil e tem 
protagonismo dos Institutos Federais. Na região sul do país, pode-se citar as Coleções da FURG (Pinho et al., 2019), do IFSC-Câmpus Florianópolis (ANDREOLI; SILVEIRA, WIDMER, 2015), de Navegantes (ROSA; WIDMER, 2020) e de Paranaguá (SILVA; KRELLING, 2019).

De acordo com Alves et al. (2010), as coleções científicas auxiliam pesquisadores focados em estudos sobre lixo marinho, possibilitando estudos mais abrangentes, sendo também instrumentos importantes de transmissão de conhecimento. Através delas, é possível expor às pessoas os problemas e impactos associados à presença de lixo, este que também pode afetar as Unidades de Conservação. A coleção científica e didática torna-se um acervo de grande importância, tanto para sensibilização da população em geral quanto para pesquisas na área.

Nesse sentido, este trabalho tem como objetivo descrever a montagem e implantação de uma coleção didático-científica de lixo no mar como ferramenta de EAMC, buscando aplicar o conhecimento científico sobre lixo marinho no município de Governador Celso Ramos (SC). Especificamente, objetiva-se aqui relatar a experiência na formação da coleção física; a criação de uma versão simplificada on-line e a elaboração e testagem dos planos pedagógicos junto a três públicos-alvo.

Espera-se que a coleção possa auxiliar o poder público em esforços mais assertivos de Educação Ambiental voltados à sensibilização dos alunos, comunidade, pescadores e turistas no combate ao lixo no mar, além de registrar informações sobre tendências e fontes de lixo na orla de Governador Celso Ramos.

\section{Materiais e Métodos}

A metodologia deste trabalho está apresentada aqui em três etapas principais, a começar com a formação física da coleção didático-científica de referência de lixo no mar; na sequência, a criação de uma versão on-line simplificada da coleção; e, por fim, a elaboração dos planos didáticos.

\section{Formação da coleção física}

A metodologia aplicada à montagem da coleção didática se deu por meio de coletas dos itens, entre o inverno de 2019 e o verão de 2020, durante pesquisa científica sobre o macrolixo praial de Governador Celso Ramos (GCR), relatado em outro artigo científico (COSTA; WIDMER 2020 manuscrito submetido para publicação).

Os itens da coleção foram coletados conforme o protocolo do Programa de Detritos Marinhos da NOAA (OPFER; ARTHUR; LIPPIATT, 2012), o qual se baseia na adoção de pontos de estudo que medem $100 \mathrm{~m}$ de comprimento paralelos à água, demarcados e divididos em 20 transectos de $5 \mathrm{~m}$ de largura. Antes do levantamento, cinco desses 20 transectos foram aleatoriamente

revista brasileira educação ambiental 
escolhidos para eliminar um eventual viés na amostragem. Cada transecto foi amostrado da margem da água até o primeiro obstáculo - vegetação de restinga, edificação ou dunas, por exemplo. O tamanho mínimo de detritos amostrados e coletados para a coleção foi de $2,5 \mathrm{~cm}$, caracterizado como macrolixo (GESAMP, 2019). Foram realizados dois pontos de estudo por praia.

Visando abranger representativamente a orla municipal, os itens foram coletados nas praias de Ganchos de Fora - P01, Palmas - P02, Praia Grande - P03, Cordas - P04 e Tinguá - P05, todas localizadas em GCR. (Figura 1).
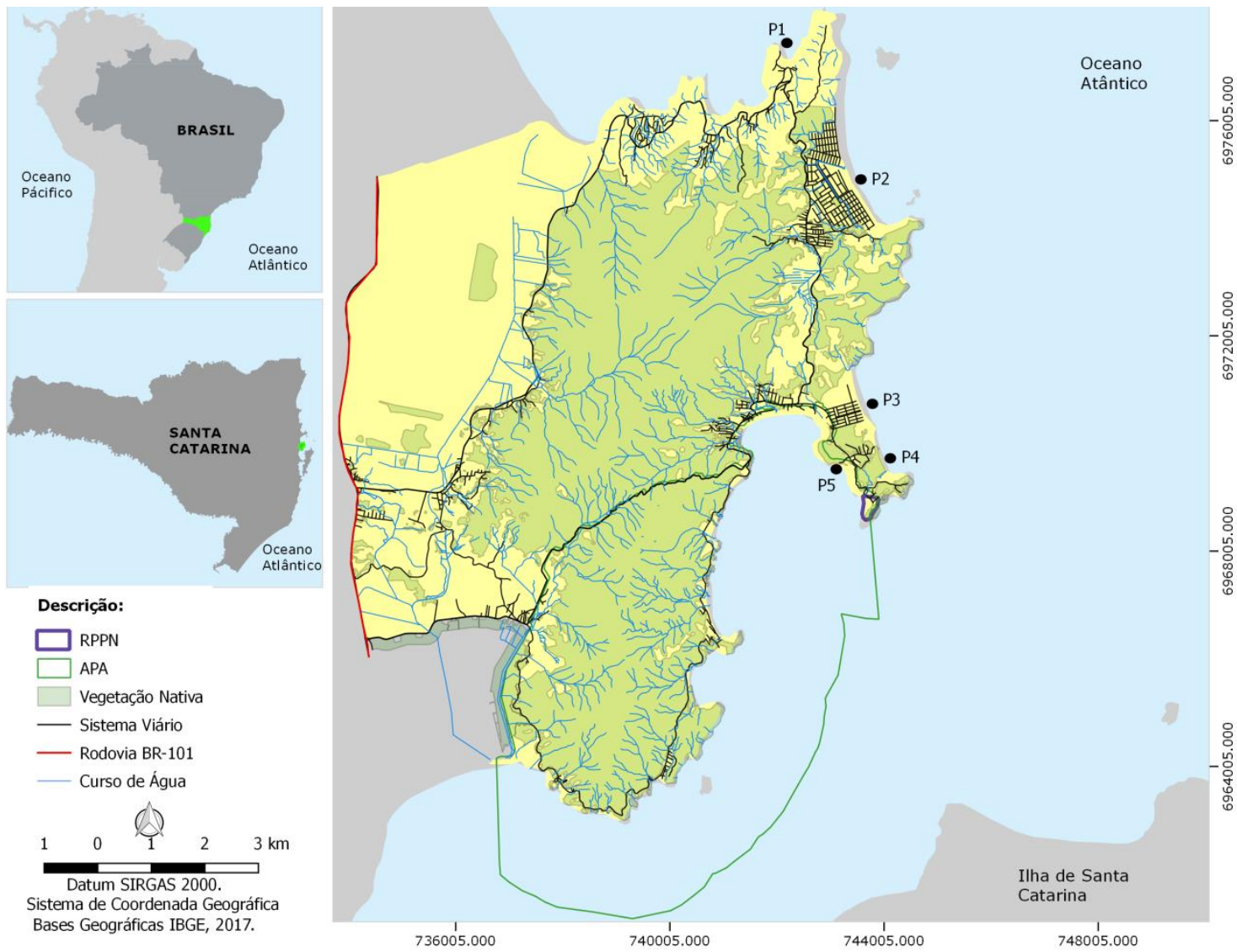

Figura 1: Mapa de localização de GCR com indicação do sistema viário, cursos de água, delimitação das unidades de conservação (Área de Proteção Ambiental de Anhatomirim e Reserva Particular do Patrimônio Nacional da Ponta do Mata Mata - RPPN), cobertura vegetal de Mata Atlântica e as praias monitoradas. A REBIO marinha do Arvoredo situa-se nas águas do Oceano Atlântico a cerca de $12 \mathrm{Km}$ a nordeste de GCR. Ela não está representada neste mapa. Fonte: Elaborado pelos autores.

São três as principais Unidades de Conservação (UC) que se relacionam com GCR. A primeira delas é a Área de Proteção Ambiental de Anhatomirim (APA Anhatomirim) criada em 1992 com o objetivo de proteger a população residente dos golfinhos Sotalia fluviatilis, além de preservar os remanescentes de Mata Atlântica e nascentes e mananciais que estão intimamente relacionados à manutenção das comunidades pesqueiras artesanais na área. $\mathrm{A}$ Reserva Particular do Patrimônio Natural da Ponta do Mata - Mata (RPPN Ponta do Mata-Mata) é uma UC menor situada em área privada localizada na 
comunidade da Armação da Piedade, com o objetivo de conservar a diversidade biológica. A Reserva Biológica Marinha do Arvoredo (REBIO Arvoredo) foi criada em 1990. Essa REBIO é formada por uma extensa área marinha com cerca de 17.600 hectares, localizada no Oceano Atlântico ao norte da Ilha de Santa Catarina (Florianópolis), a nordeste de GCR e a leste do município de Bombinhas. Ela tem como objetivo proteger amostra representativa dos ecossistemas da região costeira, suas ilhas e ilhotas, águas e plataforma continental, com todos os recursos naturais associados. A REBIO Arvoredo encontra-se a cerca de doze quilômetros da orla de GCR. Essa proximidade faz com que ela sofra influência das atividades continentais, como por exemplo, a pesca ilegal e o aporte de resíduos sólidos originários dos municípios adjacentes. Essas UC põem particularidades ao planejamento urbano de GCR, ao mesmo tempo que agregam atratividade ao município (MASCARELLO, 2011; BRASIL, 2000; SEGAL, B, et al., 2017; BRASIL,1992).

Após a coleta dos resíduos nas faixas de areia das praias, os itens foram selecionados a fim de que a coleção seja formada por amostras dos principais tipos de itens encontrados nas praias de GCR, com destaque aos itens provavelmente originados da atividade pesqueira e de usuários da praia, pois, conforme os resultados de pesquisa já realizada (COSTA; WIDMER 2020 manuscrito submetido para publicação), esses são dois atores sociais relevantes na geração de lixo marinho em GCR.

Os itens selecionados foram lavados em água corrente, em seguida, procedeu-se à secagem dos itens, colocando-os em bacias e expostos ao sol. Para o acondicionamento dos itens, foram reutilizados recipientes transparentes, previamente esterilizados. Os recipientes foram rotulados com numeração específica correspondente à ficha catalográfica (Figura 2).

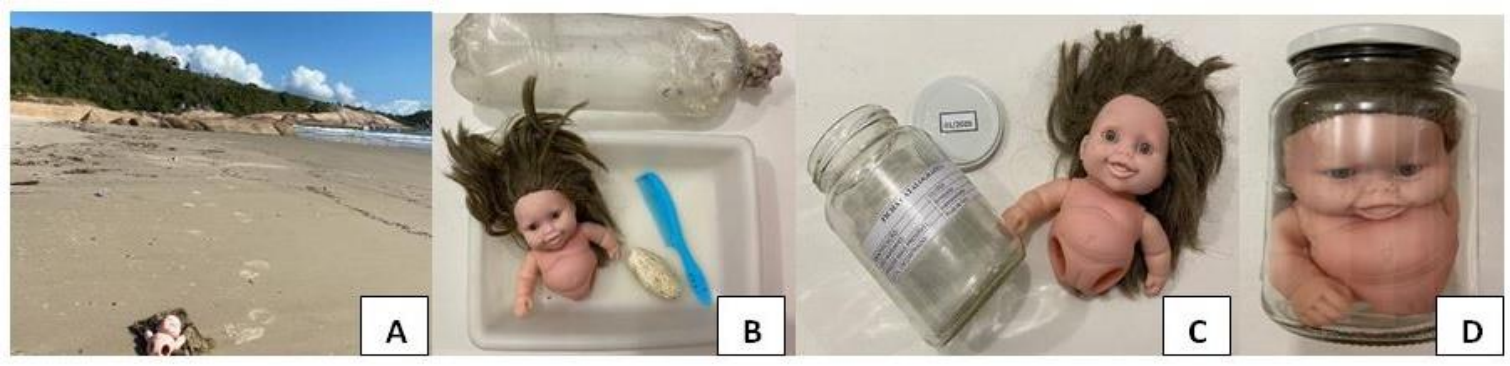

Figura 2: Montagem da coleção didática: $(A)$ coleta do lixo marinho; (B) triagem e limpeza dos materiais selecionados; $(C)$ identificação do item, conforme informações da ficha catalográfica;

(D) armazenamento. Fonte: Elaborado pelos autores.

A ficha catalográfica foi montada com informações relevantes associadas aos diversos aspectos de cada item, como o material predominante, a origem mais provável, tempo estimado de decomposição do material predominante, o risco ambiental associado ao material e à estação do ano em que foram coletados, permitindo, deste modo, uma discussão sobre o clima e suas mudanças, além da data da coleta e do nome completo do coletor. 
A coleção didático-científica foi acondicionada em estante metálica e ficará exposta em local que possibilite a melhor integração da coleção com as atividades na rede municipal de ensino.

\section{Criação de uma versão on-line simplificada da coleção}

Cerca de $25 \%$ do total de itens que compõem a coleção física foram selecionados e fotografados e um texto descritivo para cada item foi elaborado. Essas fotografias e os textos associados foram disponibilizados na página do Instagram criada especialmente para a divulgação da coleção e sensibilização quanto à problemática do lixo no mar, formando uma versão compacta e online da coleção.

\section{Planos pedagógicos}

Em parceria com a diretoria de Educação Ambiental de GCR, foram elaborados três planos pedagógicos distintos para orientar a utilização da coleção perante os seguintes públicos: alunos da rede municipal de ensino, pescadores e turistas, assim como a elaboração de um questionário para cada público-alvo. O primeiro público foi escolhido pensando em sensibilizar as futuras gerações. Os dois outros públicos foram identificados em estudo anterior como fontes relevantes do lixo praial no município. A apresentaçãoteste da coleção para os três públicos é importante para que seja possível avaliar os planos pedagógicos, ajustando-os conforme necessário.

\section{Resultados}

\section{Formação da coleção física}

A coleção didático-científica está atualmente formada por 72 itens (Figura 3). Destes, sete itens são relacionados à atividade pesqueira (anzóis, redes e cabos náuticos, por exemplo) como origem mais provável, 26 itens associados ao usuário de praias (palitos de picolé, pontas de cigarro, canudos e sandálias), 7 itens têm origem doméstica (esponja, haste flexível para limpeza auricular, enfeites de Natal) e 32 itens têm origem indeterminada (brinquedos, pente e bijuterias). A coleção também contempla os principais tipos de materiais formadores do lixo, com destaque para os itens plásticos devido ao seu uso intenso e aos seus múltiplos e complexos impactos no ambiente marinho, totalizando 40 itens. A coleção apresenta ainda alguns itens identificados como perigosos (anzóis, fragmentos de vidro e seringa).

Todos os itens ficam armazenados em recipientes de vidro e associados a uma ficha catalográfica. No Apêndice $1 \mathrm{~A}$ consta link de acesso ao Google Drive onde está disponibilizada a ficha catalográfica. Visando permitir empréstimos dos itens da coleção com o objetivo da exposição em eventos externos, foi também elaborada uma ficha de empréstimo com o intuito de garantir o controle, segurança e manutenção dos itens da coleção (Apêndice 2).

Revbea, São Paulo, V. 16, № 3: 272-287, 2021. 

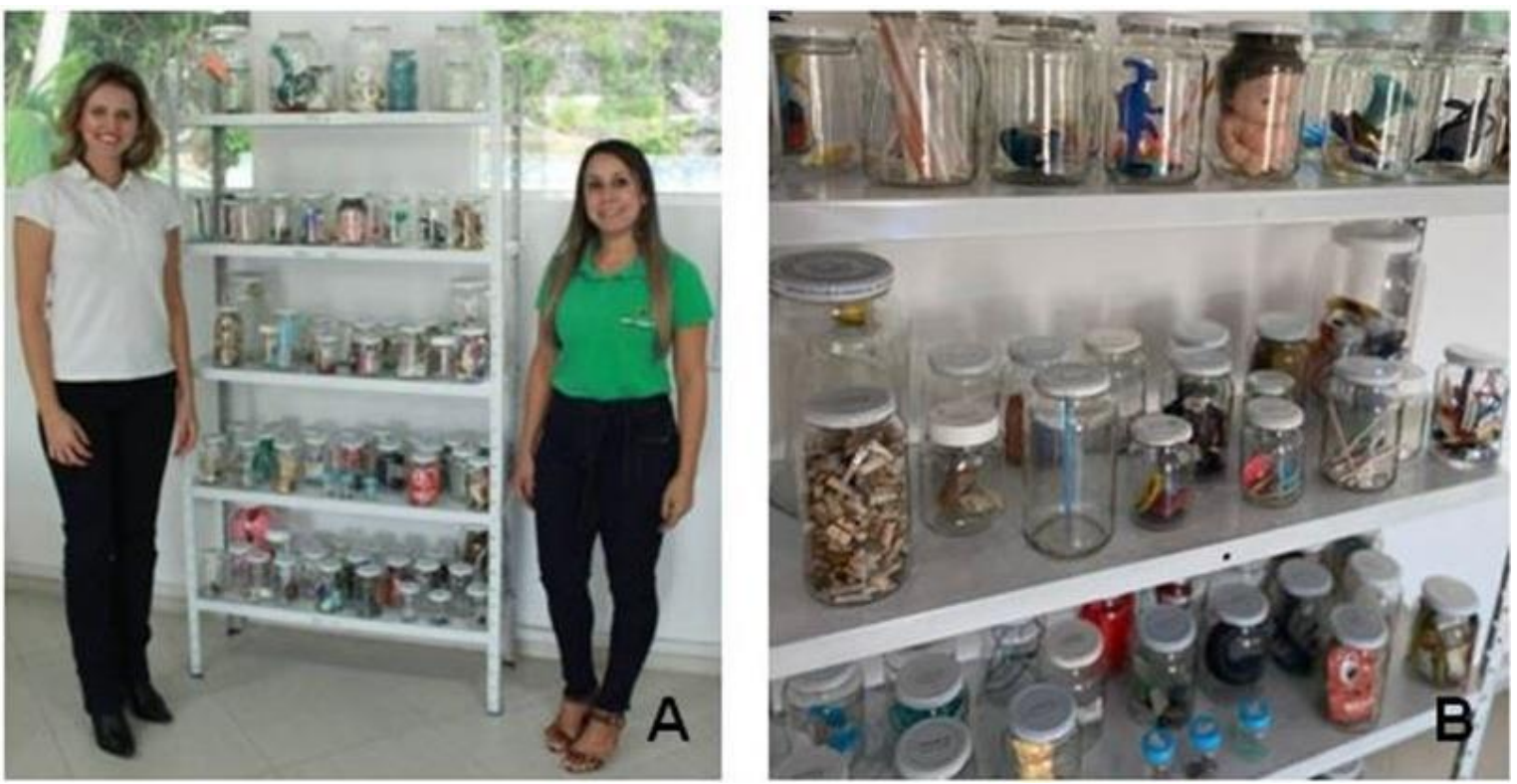

Figura 3: (A) Coleção didático-científica organizada conforme a origem mais provável do item. (B) Ilustração de itens da coleção didático-científica. Fonte: Autores.

A coleção didático-científica de lixo no ambiente marinho em Governador Celso Ramos (COLIXO-GCR) foi montada na Escola de Meio Ambiente do município, espaço pedagógico da Prefeitura Municipal que é dedicado à realização de projetos e programas ambientais (Figura 4).
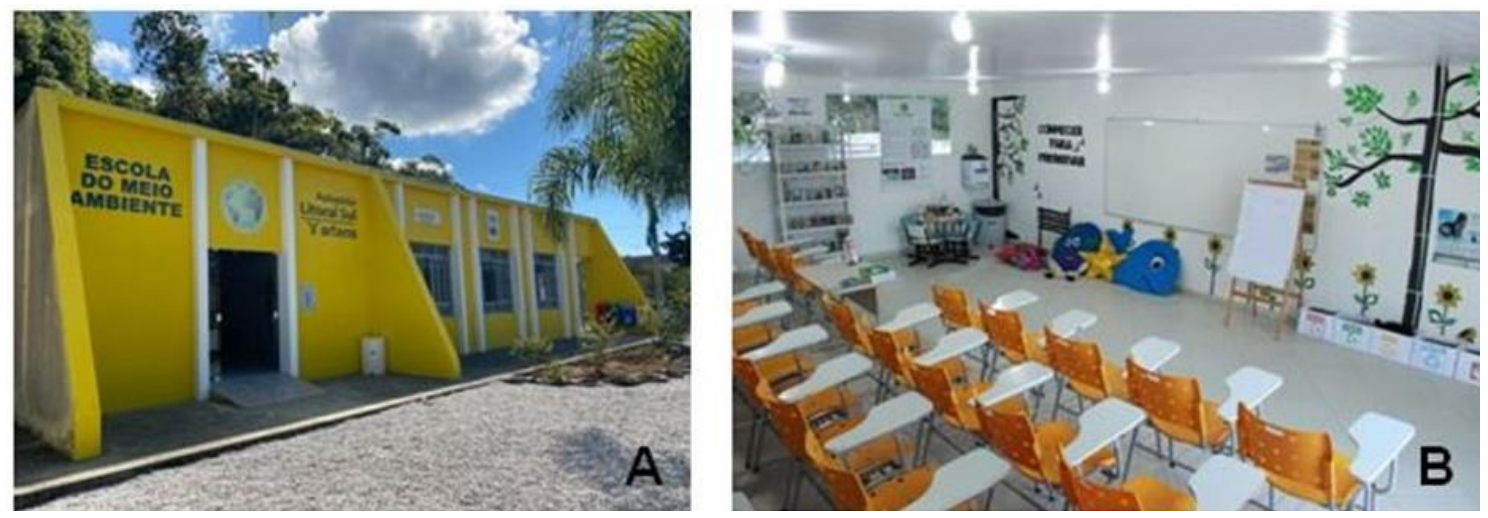

Figura 4: Local destinado à Educação Ambiental. (A) Escola do Meio Ambiente, localizada no Bairro Costeira, GCR. (B) Sala destinada à exposição da coleção didática. Fonte: Autores.

\section{Criação de uma versão on-line simplificada da coleção}

$\mathrm{O}$ ano de 2020 representou um período atípico, com isolamento social e uma série de mudanças comportamentais decorrentes da pandemia do Covid19, que tem causado a intensificação do uso de meios digitais para comunicação. Nesse sentido, optou-se por criar uma versão on-line da coleção, visando ampliar o seu alcance.

Dezoito itens da coleção didático-científica física foram selecionados para formar a coleção virtual. Com o objetivo de destacar os atores sociais 
associados às parcelas mais significativas da origem provável dos itens (pescadores e usuários da praia), foram escolhidos cinco itens associados à pesca (cabo náutico, rede, linhas de pesca, boias de isopor e anzol) e oito itens relacionados aos usuários da praia (ponta de cigarro, canudo plástico, embalagens de alimento, palito de picolé, sandália, máscara de mergulho, copo descartável e garrafa de água). Foram também escolhidos três itens domésticos (haste flexível para limpeza auricular, esponja para lavação de louças e enfeite luminoso de Natal) e dois indeterminados (seringa e garrafa PET). A seringa também representa um item perigoso.

Após seleção dos itens, foram realizados os registros fotográficos e a confecção dos textos descritivos. Foi utilizada a rede social do Instagram e a página da prefeitura municipal para a divulgação da coleção e para uma sensibilização dos internautas quanto ao lixo no mar (Figura 5).
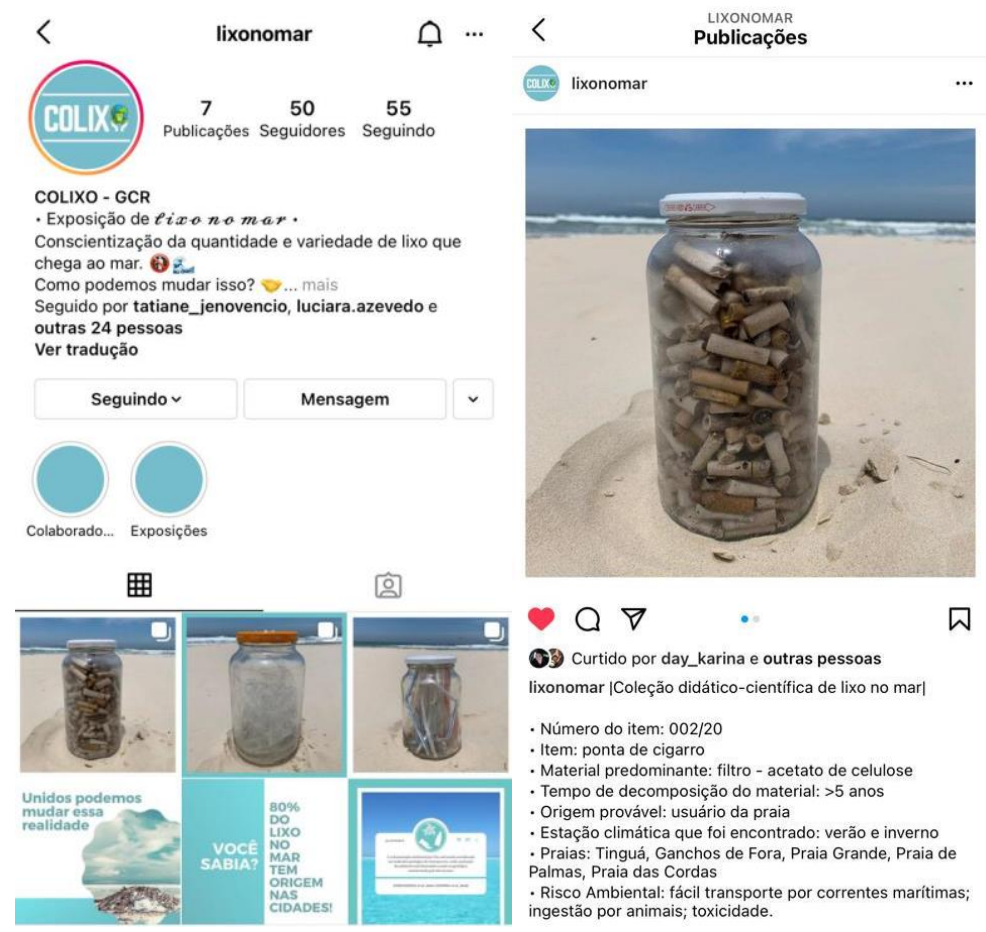

Figura 5: Página da COLIXO-GCR na rede social do Instagram. Fonte: Autores.

\section{Planos pedagógicos}

Os planos pedagógicos foram elaborados em parceria com a diretora de Educação Ambiental do município a fim de orientar a utilização da coleção perante os três diferentes públicos. No Apêndice 1B consta o link de acesso ao Google Drive onde estão disponibilizados os planos didáticos.

Esses documentos abrangeram conhecimentos das áreas de ciências do mar, sendo abordados os seguintes temas: a zona costeira, ligação do lixo no mar com as estações climáticas, a biodiversidade, o conceito de lixo marinho e suas consequências, além de ações e atitudes positivas. Os planos foram entregues à diretora de Educação Ambiental para orientar o uso da coleção na 
rede de ensino do município, pensando em sensibilizar as futuras gerações, assim como nas ações voltadas à sensibilização dos pescadores e turistas.

Para a apresentação-teste da coleção e sensibilização dos turistas foram realizadas atividades educacionais nas praias durante o verão de 2021, nos meses de janeiro e fevereiro, com a exposição de itens da coleção, destacando-se os itens cuja origem mais provável seja o usuário da praia (Figura 6) e a aplicação de um questionário (Apêndice I do Plano Didático Usuário da Praia). Durante essa apresentação foi possível identificar o interesse e a curiosidade dos usuários da praia pelo tema abordado. Através da participação ativa durante as atividades e do resultado do questionário aplicado a 48 usuários da praia, no qual $94 \%$ dos entrevistados consideram que a responsabilidade pelo lixo na praia é do próprio usuário enquanto que $6 \%$ consideram o lixo na praia de responsabilidade da prefeitura municipal, e que o percentual de $96 \%$ dos entrevistados entenderam a importância das zonas costeiras e os impactos do lixo no mar. Considerando ainda que $98 \%$ dos entrevistados gostaram da coleção e recomendariam a visitação, foi possível avaliar de forma positiva a coleção como ferramenta de Educação Ambiental na divulgação de conhecimento científico de cunho marinho-costeiro e na sensibilização da comunidade para a importância de mudanças de comportamentos visando à prevenção da poluição nos oceanos. A apresentação-teste transcorreu sem grandes surpresas e não implicou a alteração do plano pedagógico.

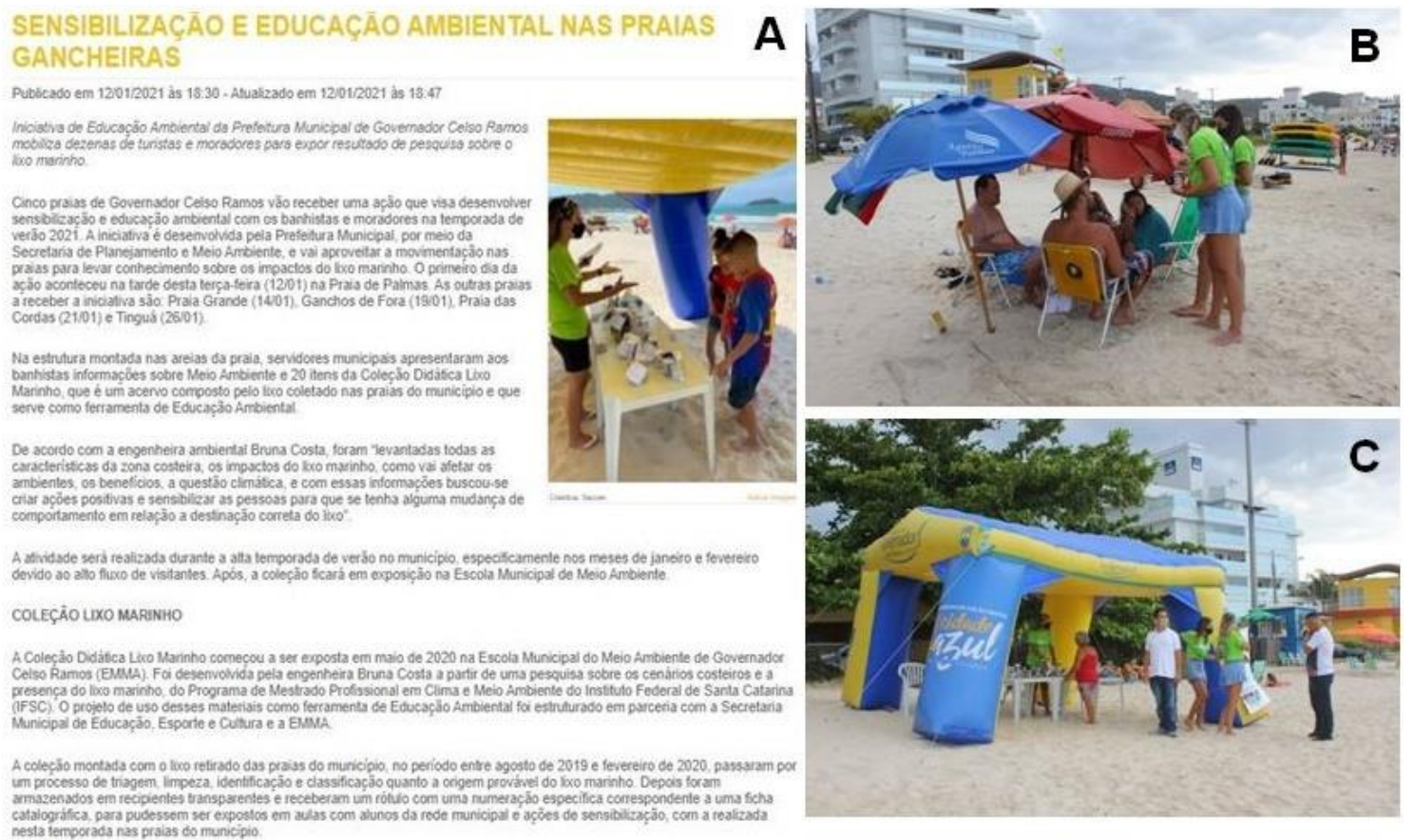

Figura 6: (A) Divulgação no site da prefeitura da exposição da coleção e sensibilização dos turistas. (B e C) Atividades educacionais na praia de Palmas para a exposição-teste da coleção didático-científica de lixo no mar. Fonte: autores. 
Também foi confeccionado um folder digital como material de apoio para ser divulgado aos usuários da praia através de aplicativos digitais como o WhatsApp e em redes sociais, visando expandir o conhecimento sobre o lixo no mar e divulgar a coleção (Figura. 7).

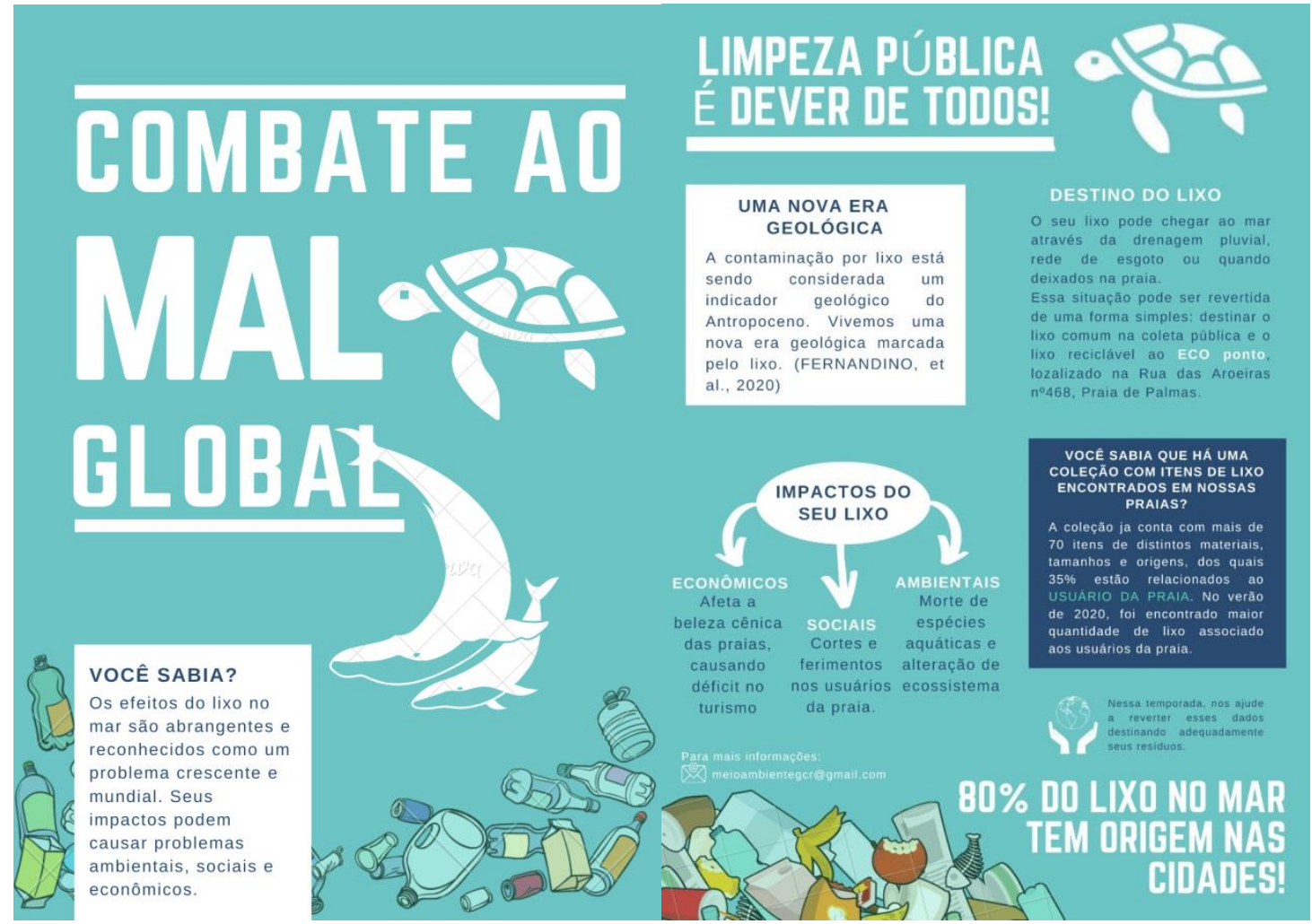

Figura 7: Folder direcionado aos usuários da praia. Fonte: Elaborado pelos autores.

Quanto aos pescadores, os itens da coleção cuja origem mais provável é a pesca, serão apresentados presencialmente durante eventos do município que tenham os pescadores como público-alvo, como em treinamentos, capacitações e no baile dos pescadores. Tais eventos, contudo, estão atualmente suspensos devido à pandemia Covid-19. Enquanto isso, o contato desse público com a coleção é possibilitado por meio da versão digital da coleção.

Similarmente, a versão digital da coleção também permite o contato dos alunos da rede municipal de ensino até que as aulas presenciais sejam retomadas e seja possível a realização da apresentação-teste da coleção.

Apesar de não terem sido inicialmente planejadas, foram realizadas atividades não presenciais como uma forma de adaptação em função do distanciamento social que a pandemia viral Covid-19 impôs à sociedade. Nesse sentido, a RE-COLIXO GCR teve sua apresentação e divulgação através de reportagens e matérias jornalísticas, em mídias sociais e entrevistas de rádio, sendo possível atuar na sensibilização das pessoas de forma indireta e imprevista durante a confecção da coleção didático-científica (Figura 8). 

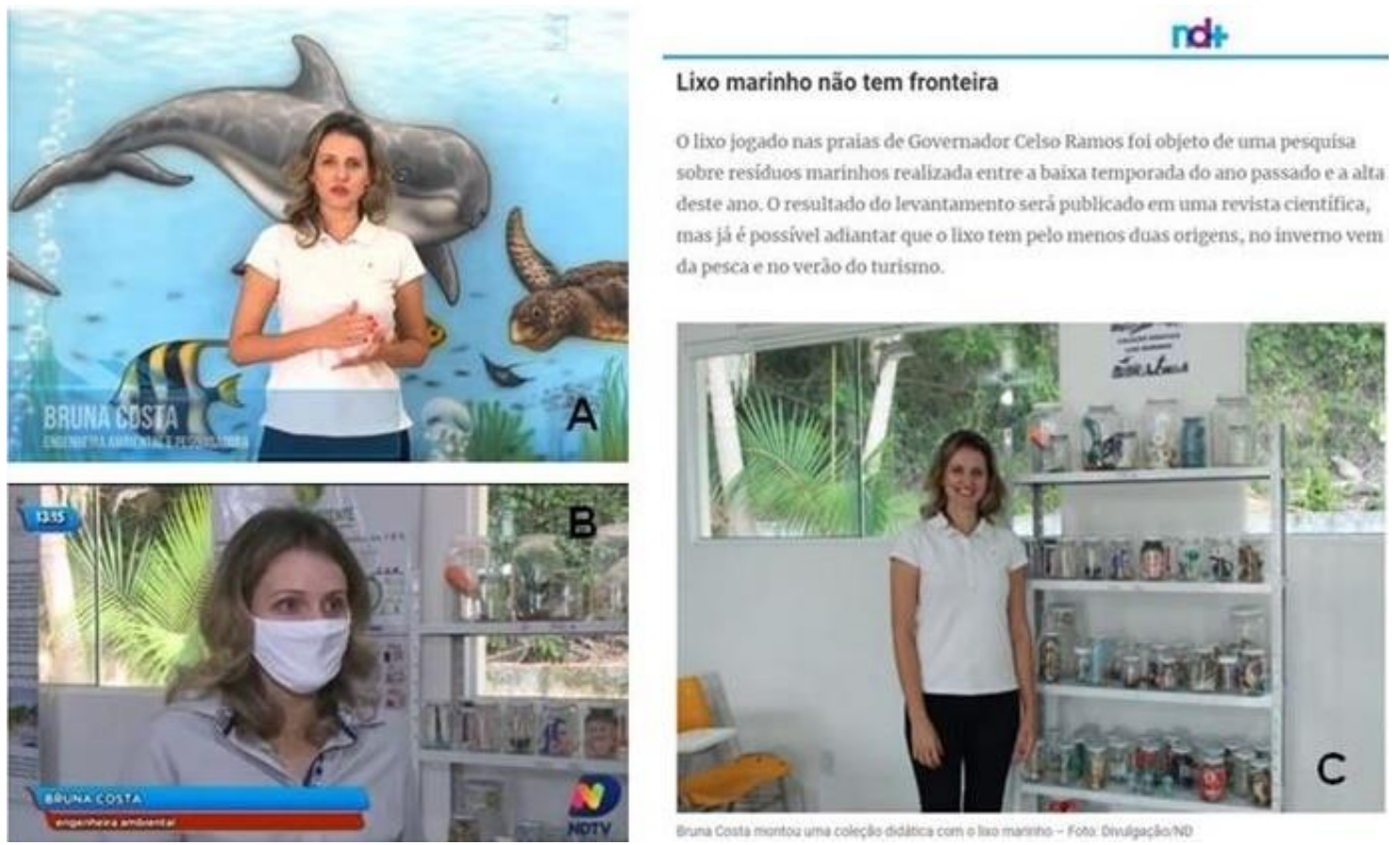

Figura 8: (A) Captura de imagem do vídeo elaborado para divulgação da coleção didático-

científica. (B) Captura de imagem de reportagem jornalística. (C) Captura de imagem de reportagem jornalística especial da semana do meio ambiente tratando do tema lixo no mar.

Fonte: (A) PMGCR, 2020; (B) NDTV, 2020; (C) ND+, 2020.

Visando inserir a COLIXO-GCR na RE-COLIXO nacional, já foram iniciadas as tratativas objetivando firmar o termo de adesão e compromisso da Prefeitura de GCR com a rede brasileira de coleções de lixo marinho.

\section{Discussão}

A COLIXO-GCR encontra-se montada com itens de macrolixo praial originado principalmente por dois atores sociais relevantes no município: usuários de praia e pescadores. A coleção possui uma pequena versão digital que tem se mostrado particularmente pertinente durante a pandemia viral Covid-19. A apresentação-teste com usuários de praia transcorreu conforme previsto e espera-se utilizar a coleção com os outros dois públicos (estudantes e pescadores) assim que as exigências do distanciamento social forem reduzidas. Nesse sentido, a autoavaliação da montagem e implantação da coleção didático-científica de referência de lixo no mar é positiva.

As unidades de conservação são espaços territoriais e recursos ambientais com características naturais relevantes, sob regime especial de administração visando conferir a elas garantias de proteção (BRASIL, 2000). Assim, a Educação Ambiental intermediada pela COLIXO-GCR contribui no sentido de prevenir a exportação de lixo marinho de origem continental para essas UCs. A REBIO marinha Arvoredo, apesar de ser uma unidade de conservação de proteção integral bastante restritiva em termos de visitação, 
apresenta uma elevada contaminação por resíduos sólidos, tanto nos costões rochosos da ilha do Arvoredo como leito marinho (MACHADO; FILLMANN, 2010). Em 2012, essa UC passou por um trabalho intenso de limpeza, no qual foram recolhidos cinco $\mathrm{m}^{3}$ de resíduos sólidos (BRASIL, 2014).

Entende-se, portanto, que a COLIXO-GCR é um instrumento dinâmico que dialoga reflexivamente com seus públicos-alvo, a exemplo do resultado apresentado por Lima et al. (2014), divulgando o conhecimento científico e promovendo a conscientização ambiental marinho-costeira, auxiliando também na proteção das unidades de conservação.

Este relato de experiência também corroborou com os resultados apresentados por Silva, Krelling (2019) e por Andreoli, Silveira, Widmer (2015), ambos trabalhos desenvolveram coleções didático-cientificas sobre lixo no mar como uma ferramenta de Educação Ambiental marinho-costeira e consideraram que a coleção pode contribuir com uma maior sensibilização da sociedade, com a divulgação do conhecimento científico.

Espera-se que a coleção em si e seus planos pedagógicos sejam alterados ao longo do tempo, incorporando melhorias e modificações de acordo com as condições e demandas da sociedade civil que frequenta GCR. Um exemplo desse dinamismo é a maior ênfase que foi dada à versão digital da coleção, representando um exemplo de como iniciativas originalmente presenciais de Educação Ambiental se adaptaram para uma nova realidade de distanciamento social e de demais práticas sanitárias associadas à pandemia Covid-19.

Todos os itens, até o momento, foram coletados em praias, mas esperase que a coleção se amplie para incluir itens coletados em outros ambientes, tais como dunas, restingas, planícies de maré, manguezais, costões rochosos e águas costeiras. Espera-se, em breve, incluir na coleção exemplares de microlixo (pellets plásticos e pequenos fragmentos menores que $5 \mathrm{~mm}$ ), permitindo a abordagem educativa dessa importante categoria de lixo marinho.

Para o município, acredita-se que será importante fazer parte da RECOLIXO, uma vez que isso permitirá a um pequeno município turístico integrarse numa rede nacional, ajudando a fortalecer esse movimento e dando visibilidade a essa problemática crescente e mundial que é o lixo no mar.

\section{Conclusões}

O lixo no mar é um problema crescente, mundial e onipresente, que traz impactos sociais, econômicos e ambientais. Dessa forma, faz-se necessário o esforço de toda a sociedade no combate a essa forma de poluição. A COLIXOGCR é uma importante ferramenta presencial e virtual que contribui localmente para o enfrentamento desse problema global, desenvolvendo a Educação Ambiental marinha e costeira baseada em fundamentos científicos e a mentalidade marítima na região sul do Brasil. 
Agradecimentos: Os autores agradecem o empenho e parceria da Sra. Luciara Azevedo de Mello, diretora de Educação Ambiental da PMGCR e da acadêmica em Engenharia Ambiental e Sanitária Suelen Silva Oliveira.

\section{Referências}

ALVES, L. H. B.; PONTES, T. L. M.; DO SUL, J. A. I.; DA COSTA, M. F. Coleção didática e de referência sobre lixo marinho: porque e como. In: Congresso Brasileiro de Oceanografia, 3, 2010, Rio Grande. Anais. Rio Grande: Associação Brasileira de Oceanografia, 2010, p. 263 - 265.

ANDRADE, J.; SCHERER, M. E. G. Decálogo da gestão costeira para Santa Catarina: avaliando a estrutura estadual para o desenvolvimento do Programa Estadual de Gerenciamento Costeiro. Desenvolvimento e Meio Ambiente. v. 29, p. 139-154, 2014.

ANDREOLI, N.; SILVEIRA, M. L. G.; WIDMER, W. M.; Coleção Didática e deReferência sobre Lixo Marinho: Uma Experiência de Montagem e Implantaçãono IFSC - Florianópolis. Caminho Aberto - Revista de Extensão do IFSC.v.1, p. 123-128, nov. 2015.

BRASIL. Decreto № 528, de 20 de maio de 1992. Declara como Área de Proteção Ambiental Anhatomirim, no Estado de Santa Catarina, a região que delimita e dá outras providências. Diário Oficial da União: seção 1, Brasília, DF, p. 6313, 21. maio 1992.

BRASIL. Lei $n^{\circ} 9.985$, de 18 de julho de 2000.Regulamenta o art. 225, $\S 1^{\circ}$, incisos I, II, III e VII da Constituição Federal, institui o Sistema Nacional de Unidades de Conservação da Natureza e dá outras providências. Diário Oficial da União: seção 1, Brasília, DF, p. 4917, v. 7. jul. 2000.

BRASIL. Lei $n^{\circ} 9.795$, de 27 de abril de 1999. Dispõe sobre a Educação Ambiental, institui a Política Nacional de Educação Ambiental e dá outras providências. Diário Oficial da União: seção1, Brasília, DF, p. 1,28 Abr.1999.

BRASIL. Ministério do Meio Ambiente. Lixo na natureza ameaça a fauna, a flora e os humanos. Brasília, DF: Ministério do Meio Ambiente, 2014. Disponível em: $\quad<$ https://www.icmbio.gov.br/portal/ultimas-noticias/4destaques/4939-lixo-na-natureza-ameaca-a-fauna-a-flora-e-os-humanos>.

Acesso em: 17 mar. 2021.

BRASIL. Ministério do Meio Ambiente. Plano de Combate ao Lixo no Mar. Brasília, DF: Ministério do Meio Ambiente, 2019. Disponível em: $<$ https://www.gov.br/mma/pt-br/assuntos/agendaambientalurbana/combate-aolixo-no-mar>. Acesso em: 16 mar. 2019.

BRASIL. Ministério do Meio Ambiente. Zona Costeira e Marinha. Brasília, DF: Ministério do Meio Ambiente [s.d.]. Disponível em: $<$ https://www.mma.gov.br/biodiversidade/biodiversidade-aquatica/zonacosteira-e-marinha.html>. Acessoem:20 out. 2019. 
CORRAINI, N. R., DE LIMA, A. S.; BONETTI, J.; RANGEL-BUITRAGO, N. Troubles in the paradise: Litter and its scenic impact on the North Santa Catarina island beaches, Brazil. Marine Pollution Bulletin, v. 131, n. April, p. 572-579, 2018.

GESAMP - Joint Group of Experts on the Scientific Aspects of Marine Environmental Protection. Guidelines or the monitoring and assessment of plastic litter and microplastics in the ocean. EUA: UNEP, 2019. Disponível em: <file:///C:/Users/Meio\%20Ambiente/Downloads/rs99e.pdf>. Acesso em: 28 mar. 2020.

LIMA, J. M. S. et al. Temáticas ambientais na escola municipal Neuza dos Santos Ribeiro, Tarumã-Mirim, Manaus (AM). Revista Brasileira de Educação Ambiental, v. 9, n.1, p. 184-190, 2014.

MACHADO, A. A., FILLMANN, G. Estudo da contaminação por resíduos sólidos na ilha do Arvoredo, reserva biológica marinha do Arvoredo - SC, Brasil. Revista de Gestão Costeira Integrada, v. 10,n. 3,p. 381-393, 2010.

MASCARELLO, M. A. Análise do grau de artificialização da orla do municipio de Governador Celso Ramos - SC. 2011. 154 f. Trabalho de Conclusão de Curso Oceonografia (Graduação em Oceonografia). Universidade do Vale do Itajaí. Itajaí.

ONU - Organização das Nações Unidas Brasil. Objetivo de Desenvolvimento Sustentável 14. Brasil, DF: ONU Brasil, c2021. Disponível em: $<$ https://brasil.un.org/pt-br/sdgs/14>. Acesso em: 03 Ago. 2020.

OPFER, S.; COURTNEY, A.; LIPPIATT, S. Marine Debris Shoreline Survey Field Guide. EUA: NOAA, 2012. Disponível em: $<$ https://marinedebris.noaa.gov/protocol-documents/shoreline-survey-fieldguide $>$. Acesso em: 01 jul. 2019.

PINHO, G. L. L. ;PINHEIRO, L. M. ; AGOSTINI, V. O. ; SOROLDONI, S. ; PECANHA, L. ; GUTERREZ, A. ; VELOSO, C. ; COUTINHO, J. . @colixovirtual. 2019; Tema: Coleção Didático-Científica de Lixo Marinho do Instituto de Oceanografia da FURG. (Rede social).

ROSA, C.; WIDMER, W. M. Coleção didático-científica de lixo marinho na praia de Navegantes/SC. Navegantes, SC. Disponível em: <https://drive.google.com/drive/u/0/folders/1n3k30Wmx7DD08oB apRDvb2jDS IwXzg > Acesso em: 04 Jan. 2021

SILVA, H. R.; KRELLING, A. P. MARIXO: desenvolvimento de uma coleção didática e científica sobre lixo marinho e análise de sua eficiência como ferramenta de Educação Ambiental. Revista Brasileira de Educação Ambiental, v. 14, n.14, p. 09-24, 23 dez. 2019.

SANTANA NETO. S. P.; CERQUEIRA, M. B.; TINÔCO, M. S.; SILVA, P. M. S. Sensibilizando estudantes do ensino fundamental I quanto à poluição por lixo marinho. Revista Eletrônica do Mestrado em Educação Ambiental. v. 26, p. 281-292, 2011. 
SEGAL, B., et al. Monitoramento ambiental da reserva biológica marinha do arvoredo e entorno. 1. ed. Florianópolis: UFSC/MAArE, 2017. 268 p.

SOUZA FILHO, J, R.; COSTA, M. F.; KRELLING, A. P.; WIDMER, W. M. Rede Brasileira de Coleções Didático-Científicas do Lixo em Ambiente Marinho (ReColixo). In: Simpósio Brasileiro sobre Praias Arenosas, 2, 2018, Florianópolis. Anais. p. $158-160$.

TORRES, H, R.; REYNOLDS, C. J.; LEWIS, A.; MULLER-KARGER, F.; KAMAL, A.; MASTENBROOK, K. Examining youth perception sand social context sof litter to improve marine debris environmental education. Environmental Education Research.v. 25, n. 9, p. 1400-1415, 2019.

WILLIAMS, A. T.; RANGEL-BUITRAGO, N. G.; ANFUSO, G.; CERVANTES, O.; BOTERO, C. M. Litter impacts on scenery and tourism on the Colombian north Caribbean coast. Tourism Management, v. 55, p. 209-224, 2016.

\section{APÊNDICE 1}

Os seguintes apêndices encontram-se disponíveis on-line nos links:

\section{Apêndice 1A: Ficha Catalográfica}

https://drive.google.com/drive/folders/1vNuLZAgInNCy brLvlhFb5jP2PkTal6Q?usp=sharing

\section{Apêndice 1B: Planos didáticos referentes aos usuários da praia, aos pescadores e aos estudantes}

https://drive.google.com/drive/folders/1imwrg37otLrciJWDT1iXPEPcuN yRZP8?usp=sharing

APÊNDICE 2

Ficha de Empréstimo

EMPRÉSTIMOS

Item №

Data Entrada

Resp.

Saída:

Entrada:

Saída:

Entrada: 